$\mathrm{Oz}$

$1-1-2005$

\title{
Migration Robots: Dialogue, the Space in Between, the Section of a Construct That Does Not Exist
}

Guillermo Garita

Follow this and additional works at: https://newprairiepress.org/oz

(c) (i) $\Theta \Theta$

This work is licensed under a Creative Commons Attribution-Noncommercial-No Derivative Works 4.0 License.

\section{Recommended Citation}

Garita, Guillermo (2005) "Migration Robots: Dialogue, the Space in Between, the Section of a Construct That Does Not Exist," Oz: Vol. 27. https://doi.org/10.4148/2378-5853.1418

This Article is brought to you for free and open access by New Prairie Press. It has been accepted for inclusion in Oz by an authorized administrator of New Prairie Press. For more information, please contact cads@k-state.edu. 


\section{Migration Robots}

Dialogue, the Space in Between, the Section of a Construct That Does Not Exist

\section{Guillermo Garita}

This essay is written under several assumptions, which give me the opportunity to establish a platform of reference for my work, my work within my practice and the work within my academic studio.

As I begin to scrutinize what we do, what we attempt to explore, the ideas that we conceive I realize that the tools we employ, the processes that we have learned are mostly limited by our ability of expression.

I begin by assuming that design is boring. Design expressions for the most part are filled with preconceived notions of what something looks like, its stylistic disposition, and its esthetic value. It refers to a state, which favors

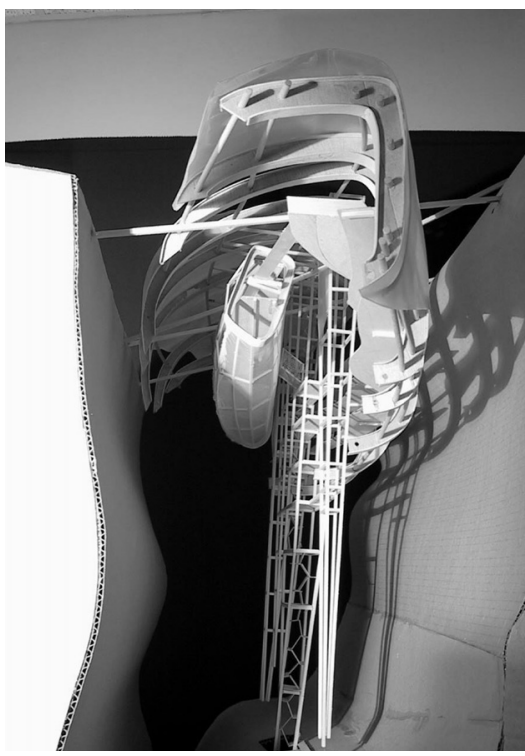

an answer over a process. It oversimplifies the mode of inquiry.

I begin by assuming that there is no discovery, rather there is the ability of uncovering. The idea of discovery is self-promoting as it embodies the notion of conquest, ownership, possession; but uncovering is finding the existing under our own terms of interpretation, it is a democratic event in which the uncovering does not state ownership allowing for it to be malleable, mutable and recyclable. The uncovering could be digested, modified and transformed. This notion of an "Uncovered Idea" comes not as a relic that has been found to remain untouched, but as a dynamic thought flexible and ever changing.

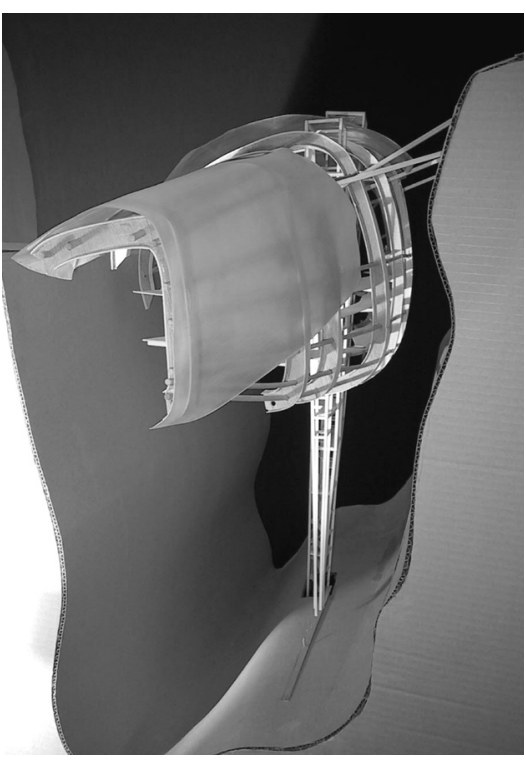

I begin by assuming that my ideas do not belong to me. An idea is a response, a response to a specific inquiry or circumstance that allows me to create a debate. I realize that the specifics of my responses are an acute reduction of countless thoughts collected through my sensory and experiences.

Process is a good word. It manifests itself as a series of events leading to a result that embodies an answer to an inquiry. I often find process connected to design; design as a process. I believe this connection is made by our conditioning to use the infinite term "design." I find process more interesting as a behavioral condition, a condition of thinking that puts in question how I feel about a specific problem. It

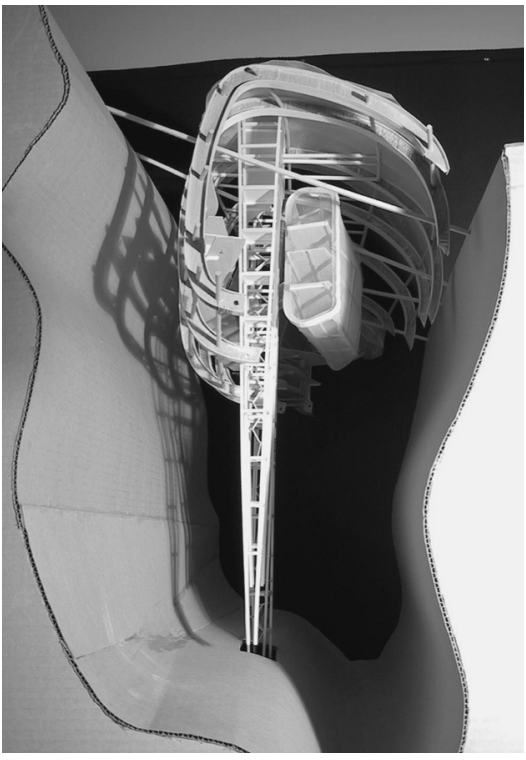

prompts my sentiments for a response to the problem of design, not how 1 design. This process is allowing me to create my own tools to work, tools of development that allow for ideas to migrate, to be transferred.

My interest in this essay lies in the Thinking Process. A thinking process set up to question the Design process, or Problem of design. A process that is self referential, a process that inquires about our responses to an imposed problem, "the (P.O.D.) problem of design", a clear and concise process that begins by questioning and assessing our actions against the P.O.D. In order to do this; I must examine the rules and guidelines that I establish to deal with the inquiries posed by the P.O.D.

There is something to be said about my responses to the P.O.D; not the responses to resolve the problem itself but the responses to the fact that a problem has been posed. Furthermore, what vehicles do I employ to attack the P.O.D? Do I draw? Do I write? Do I build? How do I begin to "design"? Do I even design? Do I deal with it rationally? Intuitively? As I begin to understand these issues at hand I realize that I am limited to the tools at my disposal; my ability to draw; my ability to write; my ability to speak; my ability to render a condition as an expression of my inner self. Does the line limit me? Does the computer limit me? How about the table where I lay the tracing paper down? How about the size of the 


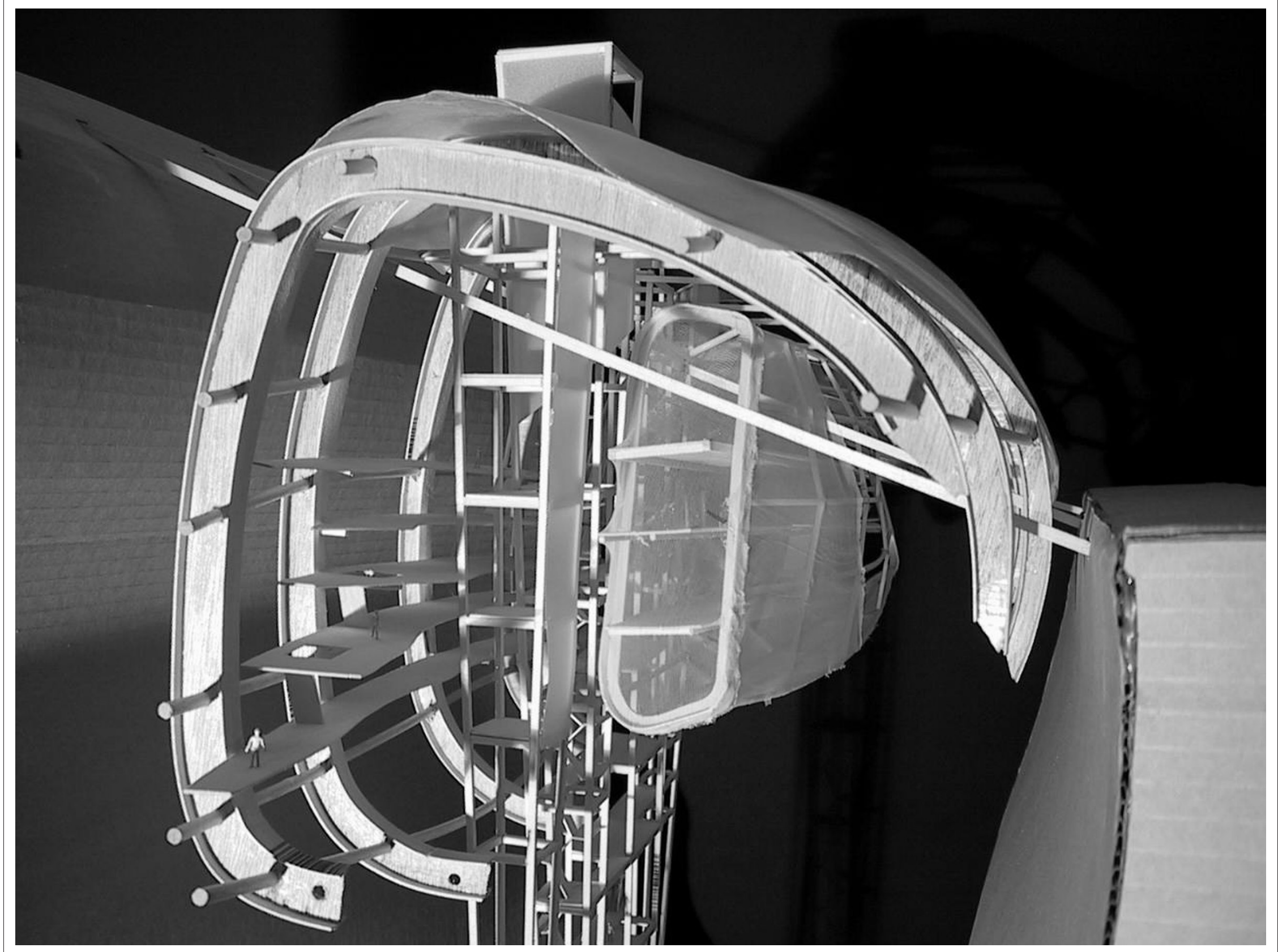



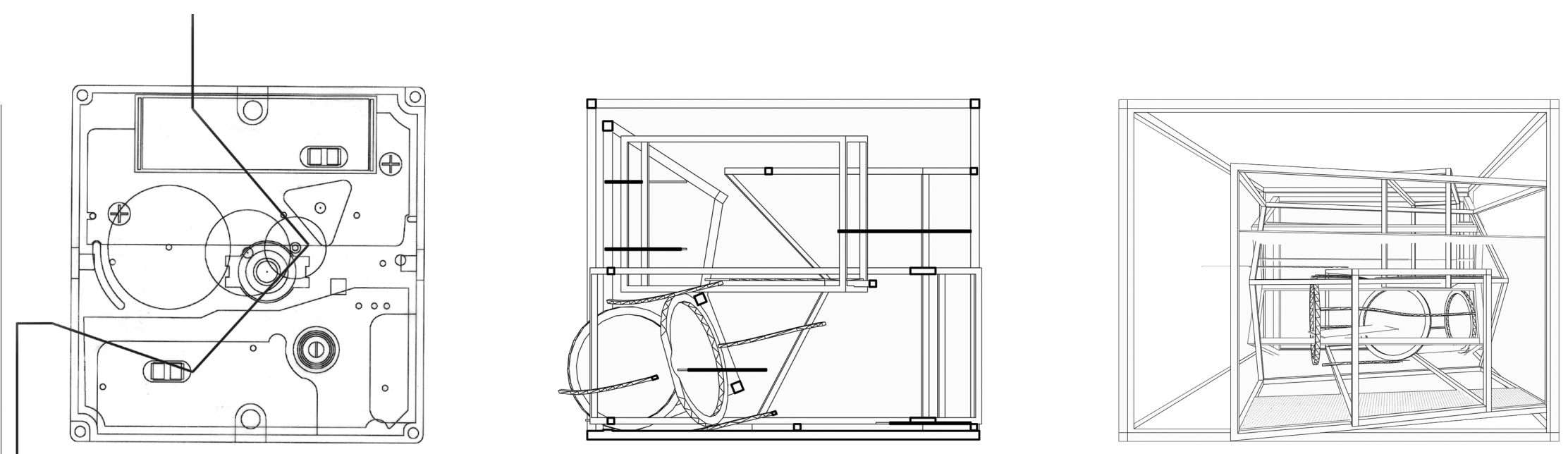

Drawings by Damian Webster
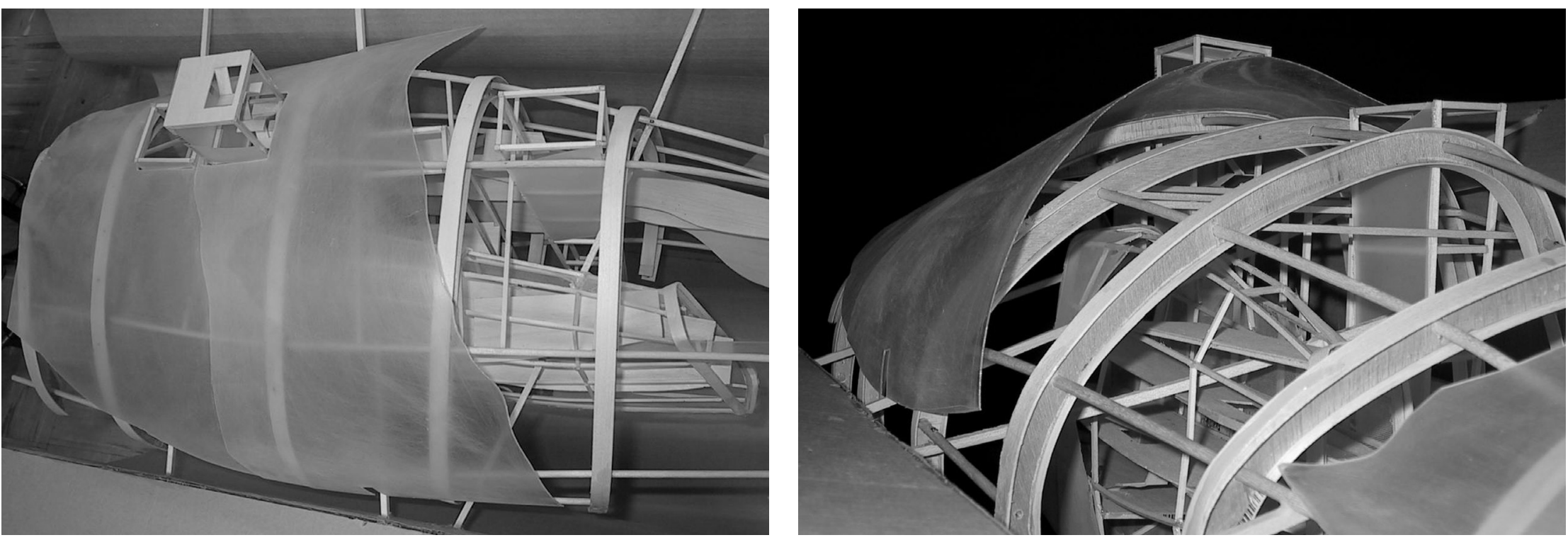

Model by Christine Roberts

paper, that spatial field defined by its physical limits? How about the scale of my room? How about the scale of my context? Do I deal with it as a tangible or intangible problem?

I begin to realize that all the tools at my disposal are not merely enough to respond to the P.O.D. I need to set up unconventional parameters to "uncover" ideas and conditions; as well, I need to create alternative migratory tools or robots to transfer ideas, responses, and thoughts. Among a few, I have selected to briefly discuss four of them: Dialogue, The Space in Between, The Section of a Construct that does not exist, the fourth migration robot, I; as I am as well a tool of migration, a actions begin to define my process of thinking and subsequently my process of responses.

\section{Dialogue}

Dialogue as a response. Dialogue allows me to have no assumptions about my responses. It allows me to deal with the P.O.D. as a philosophical question. I mean philosophical in terms of how my mind and body react to a condition, how I express my sentiments about the problem posed. The same way I respond to a new law, a new ordinance, or a new traffic light at an old intersection. The new traffic light that tells me from now on I need to stop. I need to philosophically agree in principle that the light is needed and therefore I must respect it.
As the dialogue begins, it takes me through the path of inquiry, of agree ments and disagreements, personal and collective experiences, historical references etc. We assume nothing about the P.O.D. The exercise is to construct a new experience, a new response, a recycled phenomena, one that pushes a new condition of surprise, of secrecy, one that poses a new use or program for an old stored experience, a set of memories that can be restored and repackaged for new intangible and tangible conditions. The law of adaptability; adaptability defined by the new context of inquiry.

This dialogue begins to construct an experience under very real terms of sensory, like the filmmaker constructs a 90 second scene about a specific experience. The location of my eyesight as the camera, the scale that I use to understand the length of a space, is my scale distance or is it time? Is the space narrow? Is it humid? Is it bright? I see as the light travels through, is fairly direct, but I can not see the source, my hand travels against the various horizontal and vertical terrains of textures, what do they say to me? The physical characteristics of the ground below me, the proximity of my surroundings, the smell, what I can and cannot hear.

\section{The Space in Between}

I refer to the space in between to the space where the experience exists. All the connecting spaces, the insignificant 


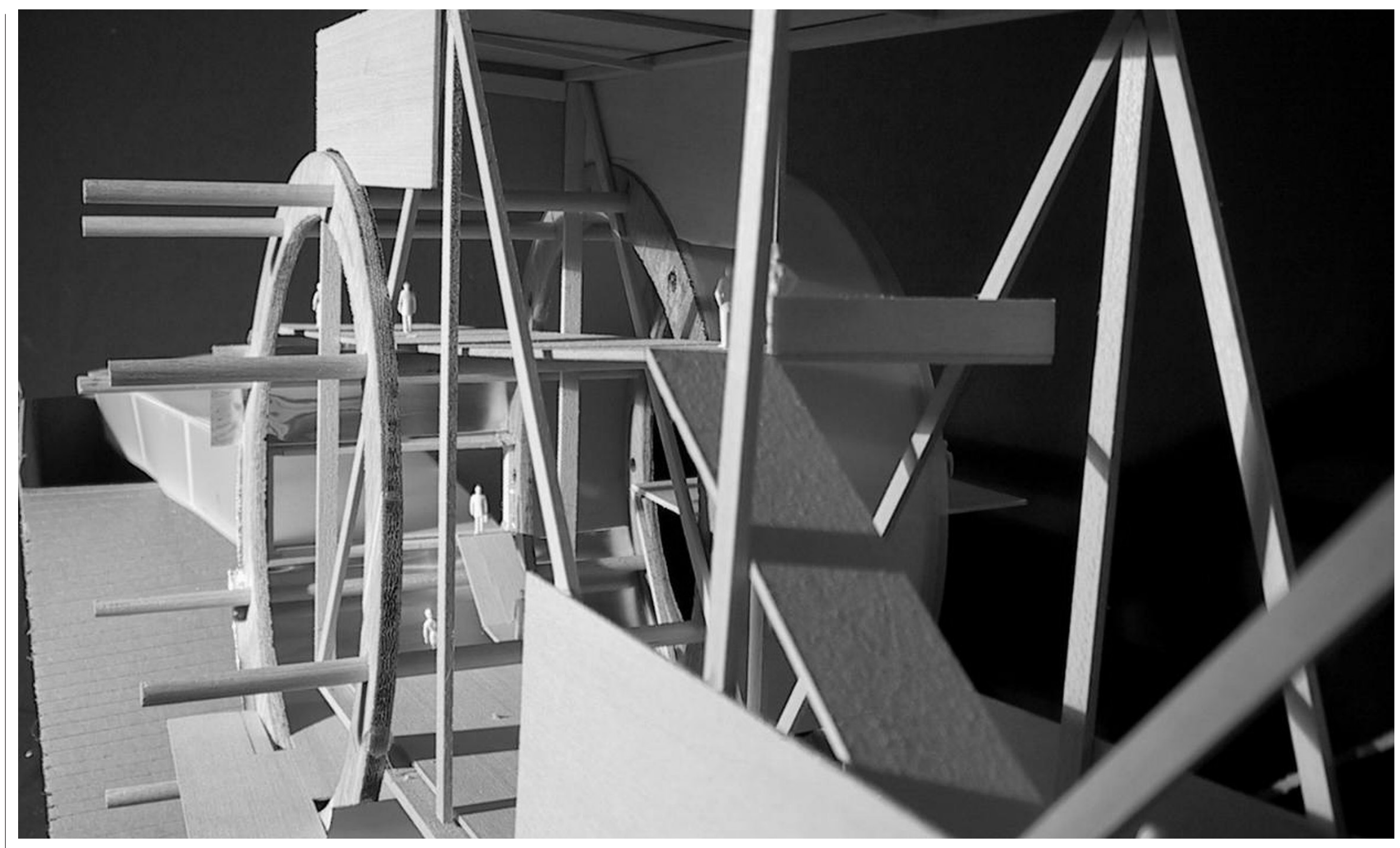

Model by studio team

conditions where no usable program (as we know it) exists, not the end space nor the beginning space but the traveled space. The threshold that holds two adjacencies, the immeasurable space typically defined by one single line representing a single boundary occupied by containment $\mathrm{A}$ and containment B. Absolving the containments from internal and external responsibilities. Along that line a boundary is defined, that boundary has an inside and an outside, it has permanency, and it has an outline that defines its existence. The space in between is by far more interesting, the two brownstones or row houses exemplify the condition. The infinite amount of party walls that outlined the boundaries of each Row house are by far more interesting as a spatial condition than the Row house itself. Let's occupy the party wall, the space in between, that spatial intersection, a point of struggle and interaction, that node of dialogue between two containments.

Georg Benrhard Riemann in the 19th century introduced the theory of Higher dimensions, and studied the properties of higher-dimensional space, he anticipated and was one of the first to discuss "Multiply Connected Spaces" or "Wormholes," whether wormholes are physically possible or just a mathematical curiosity, they give us the description of a Universe connecting with itself, or the connection of the different time eras, or also connect an infinite of parallel universes, they speak about the existence of a space in between.
Riemann's cut, the experiment of two curvilinear surfaces touching each other, one above the other, representing two parallel universes or spaces, at the moment that they touch there exists a cut, that cut is the representation of a wormhole, except that it has zero length. If I walk on the surface above as a micro being I would never know there is another parallel universe until I slip through the cut, bringing me to the other surface, allowing me to experience the other side of a multiply connected space.

\section{The Section of a Construct That Does} Not Exist

$n$. ( $k n$ str $k t$ ) Something formed or constructed from parts. 1. A concept, model, or schematic idea.
A sectional drawing composed of lines that represent boundaries, uncovered from existing spatial containments become the basic mechanism of invention, a mechanism to restore our thinking process about how we perceive space, space travel, scale of space, anonymity of space, the assembly of space, etc. The section of a Construct that does not exist becomes the platform and reference for a series of operations to inquire and experiment on how to think about space. How I express my dialogue in a physical form, how I begin the lay down the physical foundations for the Construct, concept, model. It allows me to study the Space in between, the amplification of the space in between, this amplification in terms of scale, relationships, superimpositions. This Construct 


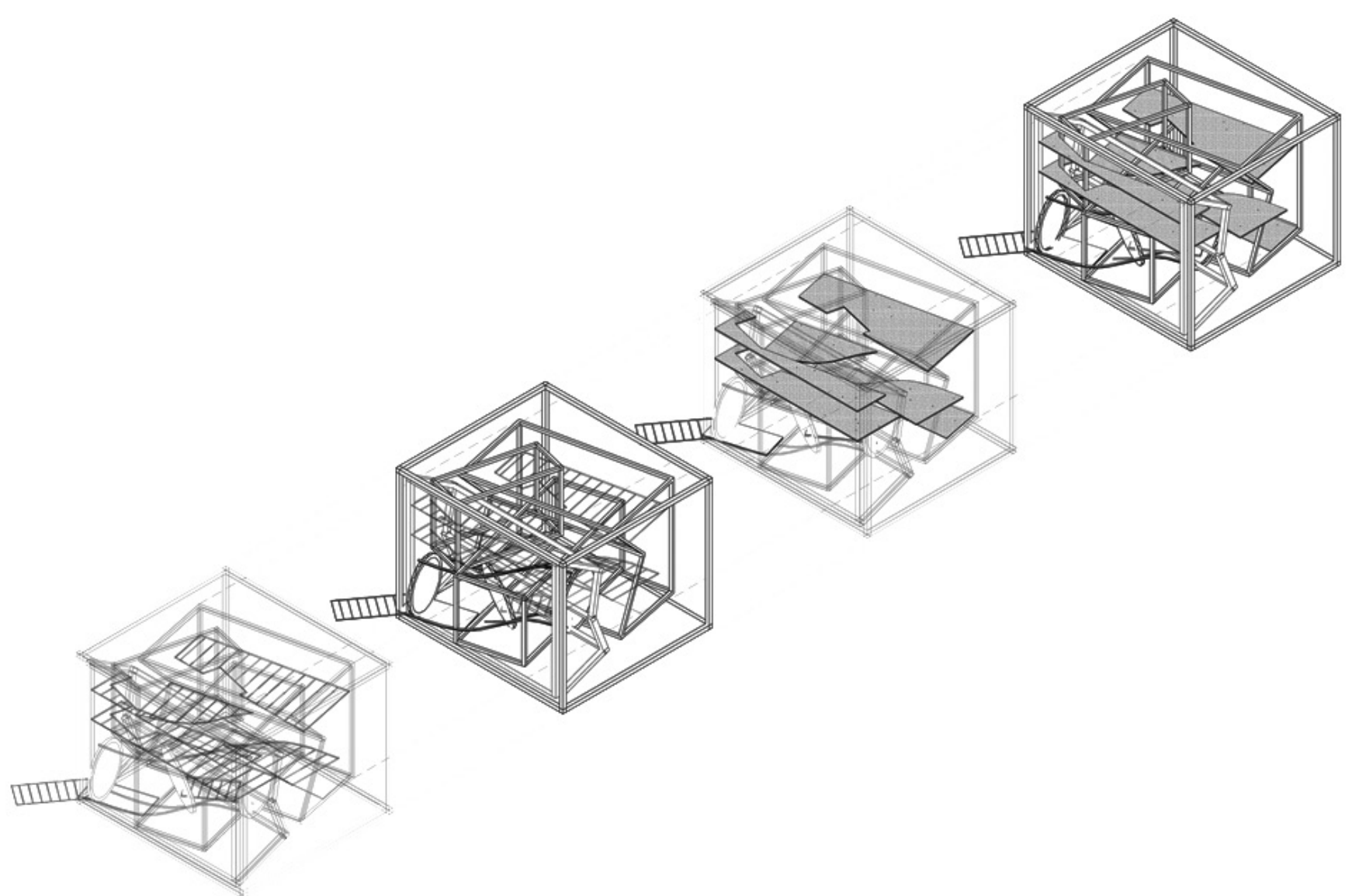

allows a framework of analysis that is only bound and limited by my thinking capacity and the rules of engagement that I set forth. All the boundaries and limitations are open ended to a very real physical confrontation with the Construct, it requests answers to inquiries of geometry, assembly, hierarchy, structure, skin, negative, positive etc, a Construct that rejects the notion of expression, and accepts making as a result.

Under these premises Space is evaluated as a phenomena that cannot be contained, nor design, a continuum to which ALL belongs. An interconnected network that suffers from momentary relapses seemingly appearing to have limits, but within the larger spectrum these limits collapse, recognizing the unification of space and man, engaged as one coexistent of the other, this unity is the infinite canvas for the beginning

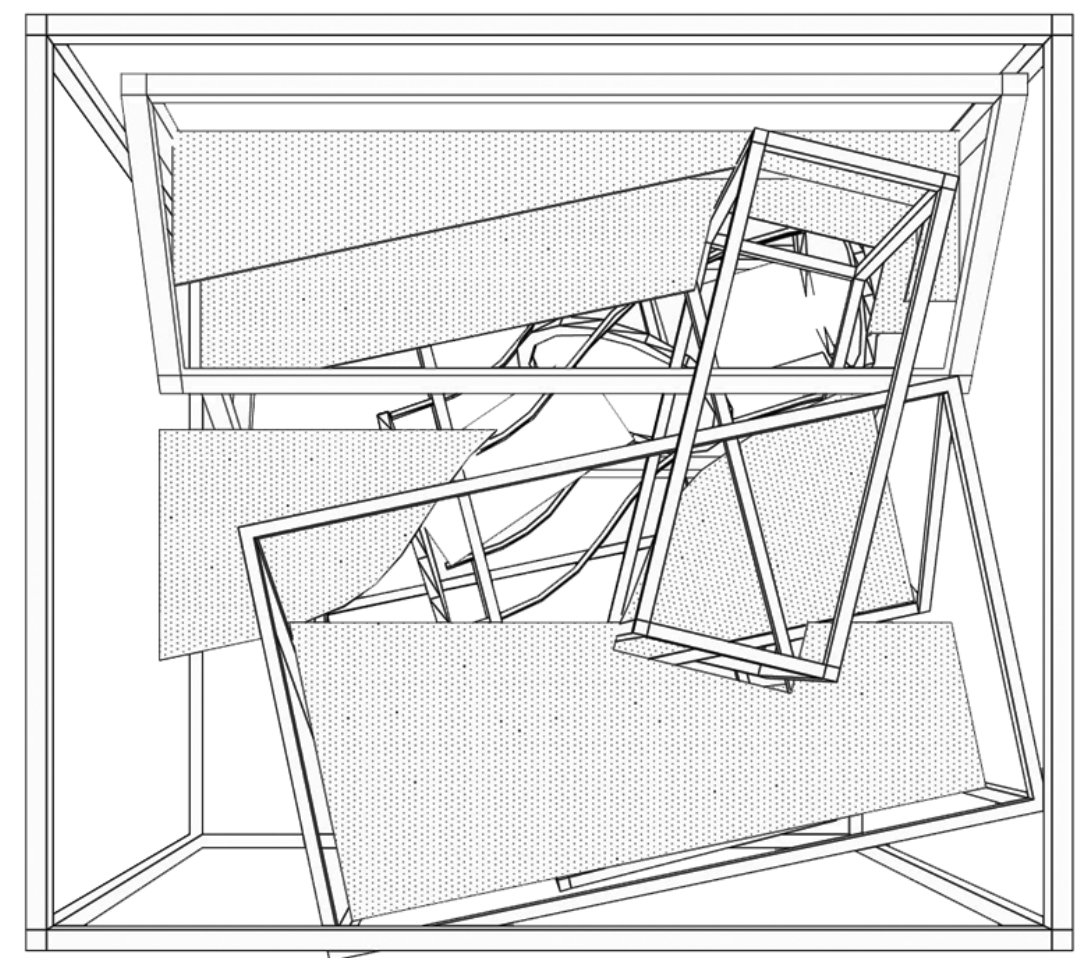

Drawing by Damian Webster

\section{Bibliography}

The American Heritage ${ }^{\circ}$ Dictionary of the English Language, Fourth Edition

Copyright $\odot 2000$ by Houghton Mifflin Company.

Published by Houghton Mifflin Company. All rights reserved.

Kaufmann, W.J. Black Holes and Warped Space-Time. San Francisco: Freeman, 1979.

Michio Kaku. Hyperspace, A scientific odyssey through parallel universes, time warps, and the 10th dimension.

Oxford University Press, 1994. 
